\title{
Effect of Continuous Negative Extrathoracic Pressure on Respiratory Mechanics and Timing in Infants Recovering from Neonatal Respiratory Distress Syndrome
}

\author{
MONIKA GAPPA, KATE COSTELOE, DAVID P. SOUTHALL, PATRICIA S. RABBETTE, \\ AND JANET STOCKS \\ Portex Anaesthesia, Intensive Therapy and Respiratory Medicine Unit, Institute of Child Health, \\ London, United Kingdom /M.G., P.S.R., J.S./; Department of Neonatal Medicine, Homerton \\ Hospital, London, United Kingdom (K.C.); and North Staffordshire Hospital Centre, \\ Stoke-on-Trent, United Kingdom [D.P.S.]
} \begin{abstract}
ABST
Changes in respiratory mechanics and timing produced
by continuous negative extrathoracic pressure (CNEP) of $-0.6 \mathrm{kPa}$ were assessed in 18 infants recovering from neonatal respiratory distress syndrome. The median gestational age was $28 \mathrm{wk}$ (range 24-36 wk). All infants were recruited before discharge from neonatal intensive care and were measured at a median postnatal age of $58 \mathrm{~d}$ (range $10-127 \mathrm{~d}$ ) and a median weight of $2.67 \mathrm{~kg}$ (range 1.99-3.77 $\mathrm{kg}$ ). All had been treated for respiratory distress syndrome; 11 were diagnosed as having chronic lung disease. At the time of the study, all infants were stable breathing room air. There was a significant decrease of the respiratory rate in all but one infant from $63.6 \pm 10.0$ to $49.3 \pm 9.1$ breaths per min (mean \pm SD) during CNEP. This was predominantly due to a marked prolongation of the expiratory time. Passive respiratory mechanics were assessed using airway occlusion techniques. Whereas respiratory system compliance $\left(C_{r s}\right)$ did not change in the infants with a normal baseline measurement, there was a significant improvement of $C_{r s}$ in the 11 infants with low $C_{r s}$ values in atmosphere: In the latter, all of whom were very-low-birthweight infants, $C_{r s}$ assessed by the multiple occlusion technique (mean \pm SD) corrected for body weight increased from $7.9 \pm 1.5$ to $9.4 \pm 1.9 \mathrm{~mL} \cdot \mathrm{kPa}^{-1} \cdot \mathrm{kg}^{-1}$ in CNEP $(p=0.012)$. There was no consistent change in respiratory system resistance in this population of 18 in-
\end{abstract}

fants. These preliminary results suggest that the beneficial effects of CNEP observed in clinical studies may be partially explained by its effects on respiratory mechanics and timing. (Pediatr Res 36: 364-372, 1994)

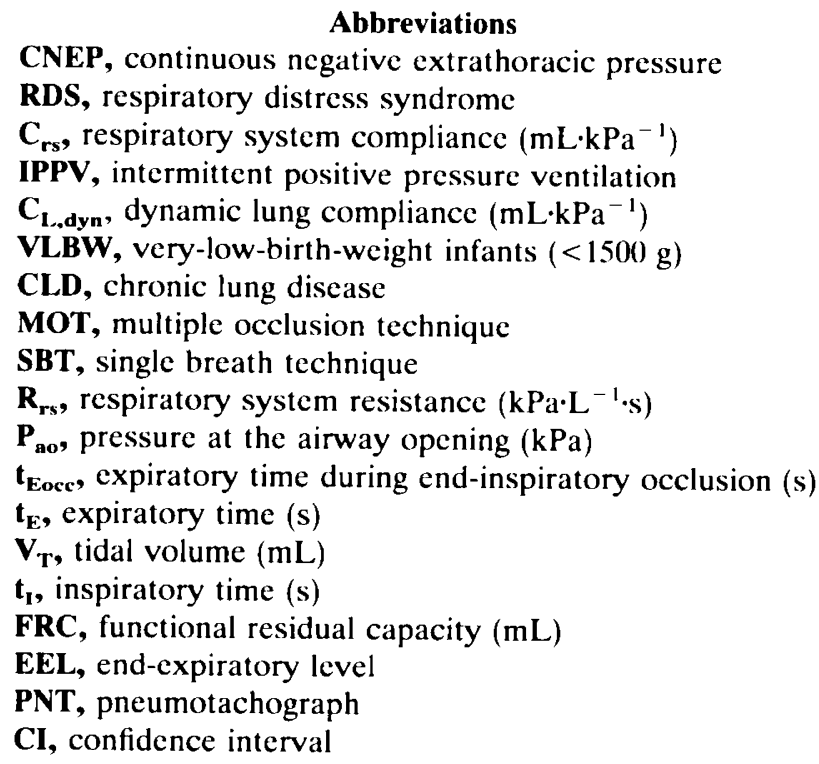

The use of negative extrathoracic pressure as a means of respiratory support has a long history dating back to the first half of the last century (1). The first apparatus designed for use in the resuscitation of neonates was

Received May 13, 1993; accepted March 17, 1994.

Correspondence: Dr. M. Gappa, Childrens' Hospital, Medical School Hannover, Konstanty-Gutschow-Str. 8, D-30625 Hannover, Germany.

Supported by the Deutsche Forschungsgemeinschaft (M.G.) and Portex Ltd. (J.S.). described in 1889. Intermittent negative extrathoracic pressure ventilation was subsequently used widely for treatment of respiratory failure in children with poliomyelitis and, during the 1960s and 1970s, both intermittent negative extrathoracic pressure and CNEP ventilation were used for the management of neonatal RDS with good clinical response (2-6). However, due to technical problems with early negative pressure systems regarding maintenance of subatmospheric pressure, upper airway 
obstruction from the neck seal, access to the patient, and temperature control, the use of CNEP was superseded by positive pressure ventilation when endotracheal tubes and respirators suitable for use in neonates were introduced. Nevertheless, it has become clear over the past years that even brief exposure to positive pressure ventilation during the neonatal period may be associated with subsequent abnormalities in lung function (7). IPPV usually requires tracheal intubation and therefore potentially increases the risk of lower airway infection. It is well recognized that positive pressure respiratory support produces barotrauma to the airways and lung tissues and probably contributes to the subsequent development of CLD. Although neonatal mortality has decreased remarkably over the last decade, there is an increase in CLD among infants surviving neonatal respiratory failure. Since reports that negative extrathoracic pressure support, either alone or in conjunction with IPPV, has the potential to overcome some of the problems introduced by positive pressure ventilation and improve the clinical course in some groups of patients $(8-11)$, there has been renewed interest in this alternative approach to the management of lung disease in neonates and infants.

A new system for applying negative extrathoracic pressure respiratory support has been designed to overcome many of the previous technical problems such as access to the infant, adequate neck seal, and temperature control (8). Preliminary results from ongoing controlled clinical trials suggest that negative extrathoracic pressure support may have benefits beyond those of conventional therapy in the management of lung disease in neonates and infants. However, little has been documented about the physiologic effects of CNEP in neonates and infants. Studies published during the 1970s in both healthy infants (12) and those suffering from RDS (13) suggested that, despite its potential clinical benefits, CNEP may have an adverse effect on $C_{L, d y n}$. In contrast, recent studies on healthy newborn piglets indicated that values of $C_{L, d y n}$ remained unchanged on initial application of CNEP but subsequently showed a significant increase after $2 \mathrm{~h}$ of continuous therapy (14). Whether these discrepancies reflect species or population differences, recent improvements in the method of applying CNEP, or differences in the techniques used to assess changes in respiratory mechanics remains unclear. Similar controversies exist with respect to the precise effect of CNEP on respiratory timing; some authors reported significant reductions in respiratory rate (15), whereas others found reductions in $V_{T}$ to be primarily responsible for the observed decrease in minute ventilation $(12,13)$.

The present study aimed to clarify some of these issues by applying recently developed methods of measuring respiratory mechanics, which do not rely on esophageal manometry, to assess the physiologic effects of CNEP in a group of preterm infants recovering from RDS.

\section{METHODS}

\section{Patients}

Twenty infants were recruited, 18 of whom could be successfully studied before discharge from the special care baby unit. Two infants failed to sleep, making collection of meaningful data impossible. The median gestational age of these infants was 28 wk (range 24-36 wk), and the median birth weight was $1.25 \mathrm{~kg}$ (range 0.69 to $3.32 \mathrm{~kg}$ ). Twelve of the 18 patients studied were VLBW (i.e. $<1500-\mathrm{g}$ ) infants. All infants had received treatment for RDS, which included in 16 the application of IPPV. CLD, as defined by oxygen dependency for more than 28 $\mathrm{d}$ plus radiologic abnormalities of the lung fields, had been diagnosed in 11 infants, all of whom were VLBW infants. At the time of the study, when the median postnatal age was $8.3 \mathrm{wk}$ (range 1.4 to $18.1 \mathrm{wk}$ ), the median postconceptional age was $36.5 \mathrm{wk}$ (range 34 to $43 \mathrm{wk}$ ), and the median weight was $2.67 \mathrm{~kg}$ (range 1.97 to 3.77 $\mathrm{kg}$ ), all infants were stable and breathing room air. The individual data of the study population are shown in detail in Table 1 . The study was approved by the local ethical committee and written informed parental consent was obtained for each infant.

\section{Study Methods}

CNEP. A negative pressure of $-0.6 \mathrm{kPa}\left(-6 \mathrm{~cm} \mathrm{H}_{2} \mathrm{O}\right)$ was applied using a system developed over the past $5 \mathrm{y}$ to overcome the technical difficulties described previously (8). It consists of a chamber with a Perspex lid on an incubator heater base with five portholes to allow easy access to the patient and the insertion of monitoring leads and treatment lines. During access to the patient, subatmospheric pressure is maintained by the use of elasticized port cuffs and an iris diaphragm at the foot end. A

Table 1. Patients*

\begin{tabular}{rrrllllll}
\hline No. & GA & PNA & Sex & Race & BW & Weight & Length & Dx \\
\hline 1 & 32 & 28 & M & Cauc & 1.760 & 2.370 & 48.2 & RDS \\
2 & 31 & 21 & M & Afr & 1.590 & 1.980 & 43.2 & RDS \\
3 & 34 & 10 & M & Cauc & 2.310 & 2.300 & 44.0 & RDS $\dagger$ \\
4 & 27 & 56 & M & Afr & 1.280 & 2.650 & 47.8 & CLD \\
5 & 32 & 22 & F & Cauc & 3.140 & 3.740 & 51.5 & RDS \\
6 & 28 & 60 & M & Afr & 1.230 & 3.000 & 47.1 & CLD \\
7 & 27 & 63 & F & Ind & 0.890 & 2.590 & 46.2 & CLD \\
8 & 27 & 62 & F & Afr & 0.999 & 2.290 & 41.5 & CLD \\
9 & 27 & 70 & M & Afr & 1.079 & 2.700 & 45.0 & CLD \\
10 & 29 & 60 & M & Mix & 1.300 & 2.490 & 48.0 & CLD \\
11 & 30 & 56 & M & Cauc & 1.480 & 2.690 & 48.5 & CLD \\
12 & 25 & 120 & M & Afr & 0.740 & 3.400 & 47.5 & CLD \\
13 & 36 & 21 & M & Cauc & 3.320 & 3.300 & 50.6 & RDS \\
14 & 24 & 125 & M & Afr & 0.780 & 3.770 & 51.4 & CLD \\
15 & 24 & 87 & M & Afr & 0.690 & 2.110 & 43.4 & CLD \\
16 & 28 & 107 & M & Asian & 0.975 & 3.320 & 48.8 & CLD \\
17 & 27 & 56 & F & Afr & 0.880 & 1.990 & 43.3 & CLD \\
18 & 34 & 21 & M & Afr & 1.800 & 2.270 & 47.8 & RDS $\dagger$ \\
\hline
\end{tabular}

* GA, gestational age (wk); PNA, postnatal age (d); BW, birth weight (kg); Dx, diagnosis; Cauc, Caucasian; Afr, Afro-Caribbean; Ind, Indian; Mix, mixed ethnic origin.

$\dagger$ No IPPV required, treated with head box oxygen only. 
safe, airtight neck seal is obtained by a rectangular latex sheet with a precut circular hole that is stretched over the infant's head and then taped to the chamber lid. The skin is protected by using an individually cut polo-neck vest, made from elasticized tubular stockinette in quadruple thickness, underneath the latex. Further protection of the skin during long-term clinical use can be achieved by using a silicone gel material collar underneath the vest, which was omitted for this short-term study. The elasticity of the latex allows a tight seal without circumferential pressure to avoid upper airway obstruction. A separate suction unit generates the negative pressure, which is monitored within the chamber by an electronic monitor.

Lung function testing. After a feeding, the infant was placed in the chamber and, after placement of the neck seal, allowed to settle at atmospheric pressure before lung function measurements were commenced.

Passive respiratory mechanics and timing were assessed both in atmospheric pressure and 5 to $10 \mathrm{~min}$ after a stepwise decrease to a continuous negative pressure of $-0.6 \mathrm{kPa}$. Attempts were made to repeat measurements in any infant who remained asleep on return to atmospheric pressure. The MOT was used to assess passive $C_{r s}$ and the SBT to assess $C_{r s}, R_{r s}$, and the time constant of the respiratory system according to well-established criteria as described in detail previously $(16,17)$. Airflow was measured using a PNT (Hans-Rudolph, Wyandotte, Kansas City) (total dead space of the apparatus, $2.1 \mathrm{~mL}$; resistance, $0.25 \mathrm{kPa} \cdot \mathrm{L}^{-1} \cdot \mathrm{s}$ at $100 \mathrm{~mL} \cdot \mathrm{s}^{-1}$ ) with the infant breathing through a Rendell-Baker face mask (size 0 and 1, Ambu International, Bath, Avon, UK), attached to a low-range pressure transducer (MP45, Validyne, Northridge, $\mathrm{CA} ; \pm 0.2 \mathrm{kPa}$ ). An airtight seal around the mask was achieved using a ring of soft silicone putty. When the peak flow was expected to exceed the range of linearity of this very-low-dead-space apparatus (i.e. $\geq 150$ $\mathrm{mL} \cdot \mathrm{s}^{-1}$ ), a Fleisch size 0 PNT was used instead (dead space $2.5 \mathrm{~mL}$, resistance $0.43 \mathrm{kPa} \cdot \mathrm{L}^{-1} \cdot \mathrm{s}$ ). With both pieces of apparatus, occlusions were performed manually using the thumb at the distal end of the PNT to minimize the dead space. The $P_{\text {ao }}$ was obtained from a port inside the PNT connected to a transducer (MP45, Validyne, \pm 5 $\mathrm{kPa}$ ) when using the Hans-Rudolph PNT and from a port inside the face mask when using the Fleisch PNT. Data display, recording, and analysis were performed using the Respiratory Analysis Program (RASP, Physio Logic Limited, Newbury, UK) on a Compaq 386e Deskpro personal computer. Airflow and pressure signals were digitized at a sampling rate of $100 \mathrm{~Hz}$ for the MOT and tidal breathing recordings and $200 \mathrm{~Hz}$ for the SBT. Volume was digitally integrated from flow.

Analysis. All data were analyzed according to wellestablished criteria $(16,17)$ using software developed in our laboratory. $\mathrm{C}_{\mathrm{rs}}$ was calculated from MOT data by taking the slope of the least square regression analysis line through the volume-pressure points of between six and 20 occlusions where $P_{\text {ao }}$ plateaus were $\geq 0.15 \mathrm{~s}$ with an $\mathrm{SD}<0.01 \mathrm{kPa}$ for all samples over that period. Only results with $r^{2} \geq 0.9$ were considered technically satisfactory. To accept data from the SBT, after endinspiratory occlusion with a $P_{\text {ao }}$ plateau $\geq 0.1 \mathrm{~s}$, the linear portion of the expiratory flow volume curve had to cover more than $40 \%$ of the expired volume with the $r^{2}$ value of the slope being $\geq 0.98$. SBT data were accepted only after careful inspection of the time-based traces to ensure that marked expiratory braking did not invalidate the results.

The strength of the Hering-Breuer reflex was assessed by calculating the prolongation of expiration during endinspiratory occlusion $\left(t_{\text {Eocc }}\right)$ in relation to the mean $t_{E}$ of at least five previous unoccluded breaths $\left[\left(t_{E o c c}-t_{E} / t_{E}\right)\right.$ $\times 100]$ (18). Tidal breathing parameters, including $V_{T}$, respiratory rate, $t_{I}$, and $t_{E}$, were calculated from at least 10 consecutive, undisturbed breaths before airway occlusions for assessing respiratory mechanics.

Attempts to measure the change in lung volume that occurred with the application of CNEP were made by continuously recording $\mathrm{V}_{\mathrm{T}}$ and measuring the difference between the volume at end-expiration during quiet breathing while CNEP was still applied and at atmospheric pressure after discontinuation of the negative pressure.

To assess the effect of the neck seal, respiratory mechanics were measured in three infants both with and without the neck seal in situ while they were breathing at atmospheric pressure. These infants were not part of the study population but were similar with respect to weight, postconceptional age, and clinical history.

All infants were studied during natural sleep, with the actual measurements confined to periods of quiet sleep, as assessed using behavioral criteria (19). Oxygen saturation was routinely monitored throughout the test using a pulse oximeter with a flexible probe attached to one foot. The total duration of negative extrathoracic pressure support for the individual infant ranged from 60 to $120 \mathrm{~min}$.

Statistics. Changes in respiratory mechanics and timing were assessed using paired $t$ tests to compare data obtained at atmospheric pressure with those obtained in CNEP. It was estimated that paired measurements in 11 infants would give a power of $90 \%$ to detect a change in $\mathrm{C}_{\mathrm{rs}}$ equivalent to $1 \mathrm{SD}$ (approximately $2 \mathrm{~mL} \cdot \mathrm{kPa}^{-1} \cdot \mathrm{kg}^{-1}$ ) significant at the $5 \%$ level. Paired measurements in 18 subjects would give a power of $95 \%$ at the $1 \%$ significance level to detect a similar difference.

\section{RESULTS}

CNEP was well tolerated by all infants after they were placed in the chamber. All infants were well saturated both at atmospheric pressure and during CNEP, with the oxygen saturation remaining between 96 and $100 \%$ throughout the test.

Respiratory timing. Application of $-0.6 \mathrm{kPa}$ CNEP resulted in a highly significant fall in respiratory rate from $63.6 \pm 10.0$ to $49.3 \pm 9.1$ (mean $\pm \mathrm{SD}$ ) breaths $/ \mathrm{min}(p<$ $0.0001,95 \% \mathrm{CI}$ of the mean of the differences -17.2 to 
-10.0). This change was apparent in all but one infant. As demonstrated in Figure 1, this reduction in respiratory rate was predominantly due to a $35 \%$ increase in the $t_{E}$ from a mean of 0.57 (SD 0.10) $\mathrm{s}$ at atmospheric pressure to 0.77 (SD 0.16) s during CNEP $(p<0.0001)$. The $t_{1}$ showed an increase from a mean of 0.42 (SD 0.07) $\mathrm{s}$ to 0.50 (SD 0.10) s $(p=0.006)$ during CNEP. The $\mathrm{V}_{\mathrm{T}}$ increased only slightly from a mean of 17.3 (SD 2.5) mL in atmospheric to 18.8 (SD 3.3) $\mathrm{mL}$ in subatmospheric pressure $(p=0.024)$, thus resulting in a significant reduction in minute ventilation.

A physiologically significant Hering-Breuer inflation reflex, as defined by an increase of $t_{E}$ during airway occlusion by at least $25 \%$ above that recorded during tidal breathing (18), was apparent at both atmospheric pressure and subatmospheric pressure in all infants in whom reliable measurements could be achieved. Due to premature arousal, no results are reported for the four infants in whom less than three technically satisfactory endinspiratory occlusions could be obtained during quiet sleep.

The absolute $t_{\mathrm{E}}\left(\mathrm{t}_{\mathrm{Eocc}}\right)$ during end-inspiratory occlusion increased on average by $0.32 \mathrm{~s}(95 \% \mathrm{CI} 0.12$ to $0.53 \mathrm{~s} ; p$ $=0.004$ ) during CNEP compared with values obtained at atmospheric pressure. However, because there was a proportional increase in both $t_{E}$ and $t_{E o c c}$ during CNEP, the calculated strength of the Hering-Breuer reflex remained unchanged with a mean prolongation of $t_{E}$ by 120 (SD 59)\% in atmospheric pressure and 111 (SD 75)\% in CNEP. These results are summarized in Table 2.

Respiratory mechanics. Instability of the EEL, failure to relax during airway occlusions, and excessive braking during expiration (20) invalidated the MOT data from two infants and SBT data from three infants (Table 3). However, successful paired measurements during both atmospheric pressure and CNEP were obtained using one technique or the other in all infants, with 13 of 18 having paired data from both techniques. Where data from both the MOT and SBT were technically satisfactory, the results were similar in all but one infant (no. 12). As summarized in Table 3, the mean $\mathrm{C}_{\mathrm{rs}}$ in atmosphere was

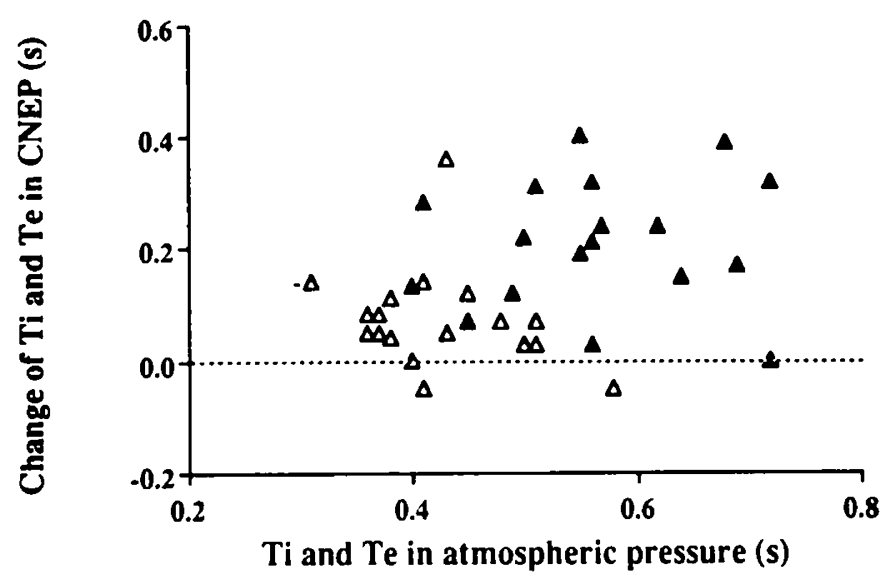

Figure 1. Change of respiratory timing with the application of $-0.6 \mathrm{kPa}$ CNEP. $\triangle=\mathrm{t}_{\mathrm{E}} ; \mathrm{wt}=\mathrm{t}_{\mathrm{r}}$.
Table 2. Timing in atmosphere and CNEP*

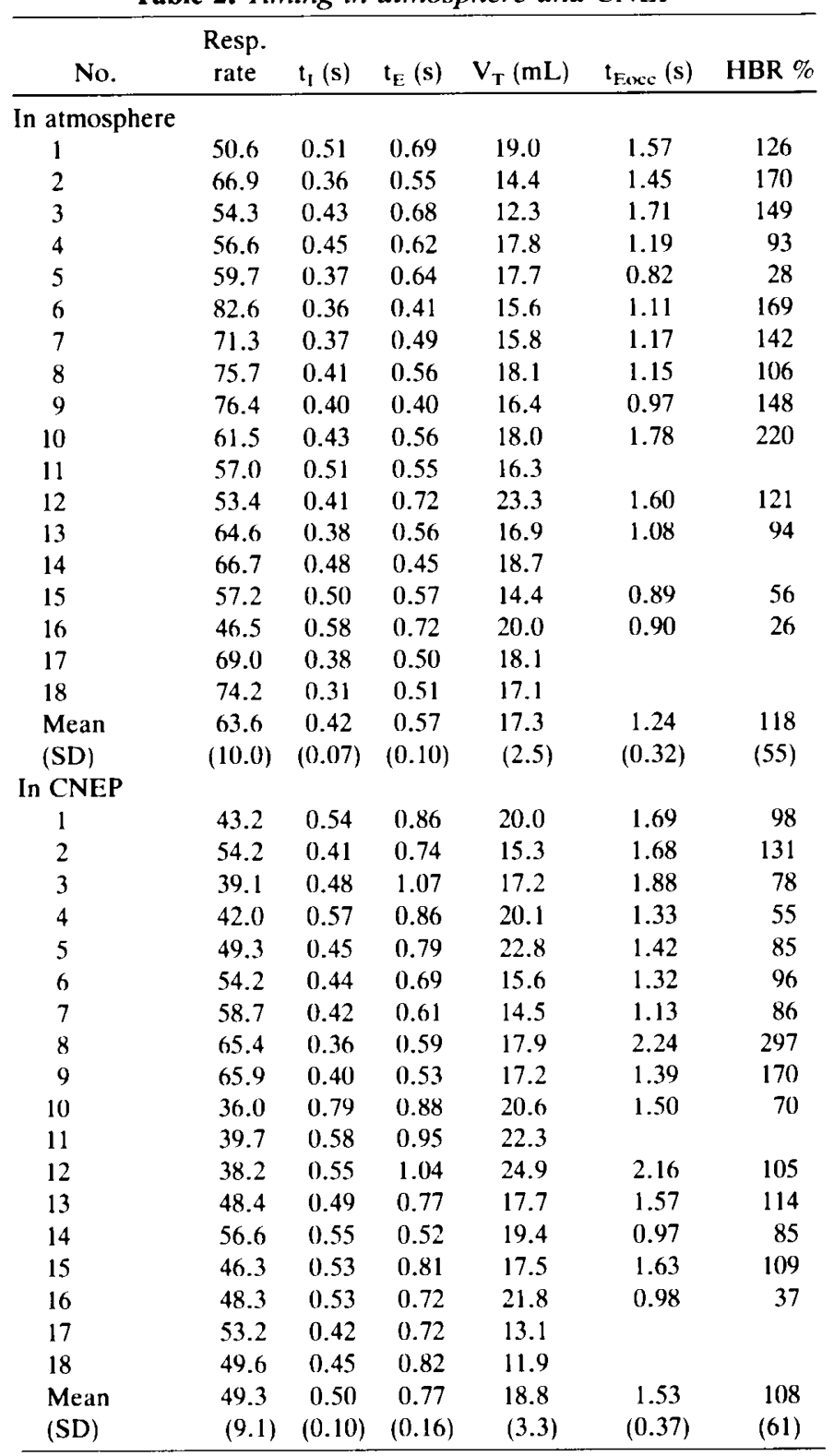

* No., infant study number; Resp. rate, respiratory rate per minute; HBR \%, strength of the Hering-Breuer reflex (see text).

24.7 (SD 7.2) $\mathrm{mL} \cdot \mathrm{kPa}^{-1}$ when using the MOT and 23.2 (SD 5.1) $\mathrm{mL} \cdot \mathrm{kPa}^{-1}$ when using the SBT. During CNEP, $\mathrm{C}_{\mathrm{rs}}$ increased to a mean of 26.8 (SD 5.4) $\mathrm{mL} \cdot \mathrm{kPa}^{-1}$ for the MOT and 27.1 (SD 4.7) $\mathrm{mL} \cdot \mathrm{kPa}^{-1}$ for the SBT. The difference reached statistical significance $(p=0.006)$ for the SBT data. However, when looking at these changes in individual infants, it became clear that this change occurred mainly in those infants with a low $\mathrm{C}_{\mathrm{rs}}$ in atmospheric pressure (Fig. 2). When corrected for body weight, 11 of the 18 infants in this study population had a baseline compliance below the lower limit of 10 $\mathrm{mL} \cdot \mathrm{kPa}^{-1} \cdot \mathrm{kg}^{-1}$ found in most healthy infants $(20-22)$. Of these 11 infants, all of whom were VLBW infants with a previous diagnosis of CLD, seven showed a marked increase of $\mathrm{C}_{\mathrm{rs}}\left(\right.$ i.e. $\left.>1.5 \mathrm{~mL} \cdot \mathrm{kPa}^{-1} \cdot \mathrm{kg}^{-1}\right)$ when CNEP was applied. In the remaining four, there was no signifi- 
Table 3. Respiratory mechanics in atmosphere and CNEP*

\begin{tabular}{|c|c|c|c|c|c|c|c|c|c|}
\hline No. & $\begin{array}{c}\begin{array}{c}\mathrm{C}_{\mathrm{rs}-\mathrm{MOT}} \\
\left(\mathrm{mL} \cdot \mathrm{kPa}^{-1}\right)\end{array} \\
\end{array}$ & $95 \% \mathrm{CI}$ & i'cept & $\begin{array}{c}\begin{array}{c}\mathrm{C}_{\mathrm{rs}-\mathrm{SBT}} \\
\left(\mathrm{mL} \cdot \mathrm{kPa}^{-1}\right)\end{array} \\
\end{array}$ & SD & i'cept & $R_{r s}$ & SD & $\tau_{\mathrm{rs}}$ \\
\hline \multicolumn{10}{|c|}{ In atmosphere } \\
\hline 1 & 23.5 & $19.0-28.0$ & $\begin{array}{r}11.1 \\
2.8\end{array}$ & 23.1 & 1.4 & 2.7 & 8.7 & 1.7 & 0.21 \\
\hline $\begin{array}{l}2 \\
3\end{array}$ & $\begin{array}{l}22.6 \\
29.5\end{array}$ & $\begin{array}{r}19.2-26.0 \\
23.5-35.4\end{array}$ & 7.3 & 28.4 & 1.6 & 4.5 & 10.9 & 1.4 & 0.32 \\
\hline $\begin{array}{l}3 \\
4\end{array}$ & $\begin{array}{l}29.5 \\
22.4\end{array}$ & $\begin{array}{l}23.5-35.4 \\
19.5-25.3\end{array}$ & 5.4 & 20.4 & 1.1 & 1.7 & 9.3 & 1.0 & 0.19 \\
\hline $\begin{array}{l}4 \\
5\end{array}$ & $\begin{array}{l}22.4 \\
42.9\end{array}$ & $\begin{array}{l}19.5-25.3 \\
35.8-50.1\end{array}$ & 8.5 & & & & & & \\
\hline $\begin{array}{l}5 \\
6\end{array}$ & $\begin{array}{l}42.9 \\
17.9\end{array}$ & $\begin{array}{l}35.8-50.1 \\
13.5-22.2\end{array}$ & 5.8 & 21.0 & 0.4 & 4.4 & 8.5 & 0.2 & 0.18 \\
\hline $\begin{array}{l}6 \\
7\end{array}$ & $\begin{array}{l}17.9 \\
19.8\end{array}$ & $\begin{array}{l}13.5-22.2 \\
16.3-23.4\end{array}$ & 7.2 & 18.5 & 2.5 & 3.1 & 14.0 & 3.3 & 0.26 \\
\hline $\begin{array}{l}7 \\
8\end{array}$ & & $16.3-23.4$ & & 28.7 & 2.0 & 4.7 & 5.5 & 0.4 & 0.16 \\
\hline $\begin{array}{l}8 \\
9\end{array}$ & 18.9 & $16.4-21.5$ & 2.7 & 21.5 & 1.0 & 4.1 & 7.5 & 0.7 & 0.16 \\
\hline $\begin{array}{r}9 \\
10\end{array}$ & 16.9 & $12.2-21.6$ & 3.9 & 19.4 & 1.3 & 2.8 & 10.4 & 0.7 & 0.20 \\
\hline $\begin{array}{l}10 \\
11\end{array}$ & 31.6 & $26.1-36.6$ & 4.9 & 32.4 & 2.7 & 4.8 & 8.3 & 0.4 & 0.27 \\
\hline $\begin{array}{l}11 \\
12\end{array}$ & 30.3 & $25.1-35.5$ & 16.8 & 19.3 & 1.9 & 2.5 & 18.6 & 2.7 & 0.36 \\
\hline $\begin{array}{l}12 \\
13\end{array}$ & 29.6 & $23.5-35.7$ & 4.9 & 32.2 & 1.4 & 4.6 & 12.4 & 0.8 & 0.40 \\
\hline $\begin{array}{l}13 \\
14\end{array}$ & 28.6 & $23.9-33.2$ & 12.3 & 22.0 & 2.6 & 4.5 & 10.1 & 0.5 & 0.23 \\
\hline $\begin{array}{l}14 \\
15\end{array}$ & 16.6 & $14.5-18.6$ & 1.8 & 15.3 & 1.0 & 0.8 & 10.8 & 1.9 & 0.17 \\
\hline $\begin{array}{l}15 \\
16\end{array}$ & 26.8 & $20.6-32.9$ & 7.3 & 24.9 & 2.6 & 3.2 & 9.3 & 1.0 & 0.24 \\
\hline $\begin{array}{l}16 \\
17\end{array}$ & 14.5 & $10.5-18.5$ & 5.0 & & & & & & \\
\hline $\begin{array}{l}17 \\
18\end{array}$ & 26.7 & $21.4-32.0$ & 6.8 & 21.3 & 2.3 & 4.7 & 13.1 & 2.7 & 0.23 \\
\hline $\begin{array}{l}18 \\
\text { Mean }\end{array}$ & 24.7 & & 6.8 & 23.2 & 1.7 & 3.5 & 9.7 & 1.3 & 0.24 \\
\hline $\begin{array}{l}\text { Mean } \\
\text { (SD) }\end{array}$ & (7.1) & & $(3.8)$ & $(5.1)$ & $(0.7)$ & $(1.2)$ & $(4.0)$ & $(0.9)$ & $(0.07)$ \\
\hline \multirow{2}{*}{\multicolumn{10}{|c|}{$\begin{array}{c}\text { In CNEP } \\
1\end{array}$}} \\
\hline 1 & & & & & & & & & \\
\hline 2 & 25.8 & $22.8-28.8$ & 0.3 & 24.9 & 1.4 & 0.4 & 6.7 & 0.4 & 0.18 \\
\hline 3 & 26.2 & $19.5-32.8$ & 0.8 & 30.2 & 1.5 & 1.5 & 9.2 & 1.5 & 0.29 \\
\hline 4 & 28.3 & $25.6-30.9$ & 3.0 & 25.8 & 1.5 & 0.8 & 6.0 & 0.6 & 0.16 \\
\hline 5 & 37.4 & $22.0-52.7$ & 0.0 & 35.9 & 2.1 & 1.2 & 7.3 & 0.8 & 0.26 \\
\hline 6 & 24.4 & $20.0-28.9$ & 1.1 & 22.1 & 2.2 & 0.3 & 6.6 & 1.2 & 0.15 \\
\hline 7 & 29.5 & $23.3-35.8$ & 5.0 & 22.9 & 2.1 & 1.1 & 9.5 & 1.1 & 0.22 \\
\hline 8 & & & & 24.7 & 2.5 & 1.4 & 7.3 & 1.1 & 0.18 \\
\hline 9 & 28.5 & $20.2-36.9$ & 3.5 & 28.7 & 2.1 & 3.8 & 7.3 & 0.6 & 0.21 \\
\hline 10 & 25.5 & $18.7-32.3$ & 4.9 & 26.5 & 1.7 & 0.5 & 7.4 & 0.3 & 0.19 \\
\hline 11 & & & & 32.2 & 1.5 & 1.7 & 10.9 & 1.3 & 0.35 \\
\hline 12 & 33.6 & $28.4-38.7$ & 5.1 & 28.7 & 1.8 & 0.7 & 14.6 & 1.3 & 0.42 \\
\hline 13 & 29.1 & $21.8-36.4$ & 0.8 & 33.5 & 2.2 & 0.3 & 7.0 & 0.7 & 0.23 \\
\hline 14 & 24.1 & $18.5-29.7$ & 3.8 & 19.8 & 0.7 & 1.4 & 8.5 & 0.3 & 0.18 \\
\hline 15 & 24.2 & $21.3-27.0$ & 3.5 & 23.4 & 1.5 & 5.4 & 12.7 & 3.9 & 0.32 \\
\hline 16 & 30.7 & $27.1-34.3$ & 5.4 & 32.0 & 2.0 & 1.7 & 7.2 & 1.2 & 0.24 \\
\hline 17 & 12.3 & $9.5-15.1$ & 5.2 & & & & & & \\
\hline 18 & 25.3 & $21.1-29.5$ & 0.8 & 22.6 & 1.3 & 0.6 & 7.5 & 0.5 & 0.18 \\
\hline Mean & 26.8 & & 2.8 & 27.1 & 1.8 & 1.4 & 8.5 & 1.1 & 0.24 \\
\hline (SD) & $(5.4)$ & & $(2.0)$ & (4.7) & $(0.4)$ & $(1.4)$ & $(2.4)$ & $(0.8)$ & $(0.08)$ \\
\hline
\end{tabular}

* No., infant study number; i'cept, volume intercept $(\mathrm{mL})$; $\tau_{\mathrm{rs}}$, time constant of the respiratory system.

cant change, with the two sets of results being within 0.7 $\mathrm{mL} \cdot \mathrm{kPa}^{-1} \cdot \mathrm{kg}^{-1}$. One of the four infants in whom $\mathrm{C}_{\mathrm{rs}}$ remained relatively unchanged subsequently developed clinical evidence of mild upper airway obstruction. On average, the $\mathrm{C}_{\mathrm{rs}}$ corrected for body weight of these 11 infants increased from 7.9 (SD 1.5) to 9.4 (SD 1.9) $\mathrm{mL} \cdot \mathrm{kPa}^{-1} \cdot \mathrm{kg}^{-1}$ with the MOT and from 8.0 (SD 2.2) to 9.5 (SD 1.9) $\mathrm{mL} \cdot \mathrm{kPa}^{-1} \cdot \mathrm{kg}^{-1}$ with the SBT. This change was statistically significant for both the MOT and SBT $(p$ $=0.012$ and 0.019 , respectively). The only infant to show a small decrease of $\mathrm{C}_{\mathrm{rs}}$ during CNEP (no. 5) was the one with the highest recorded values at atmospheric pressure.

Of the 15 infants in whom paired measurements of $R_{r s}$ were available, 10 showed a fall in $R_{r s}$ of at least $15 \%$ on application of CNEP, the largest changes (up to $44 \%$ ) being observed in those infants with the highest resistance values at atmospheric pressure. In contrast, three

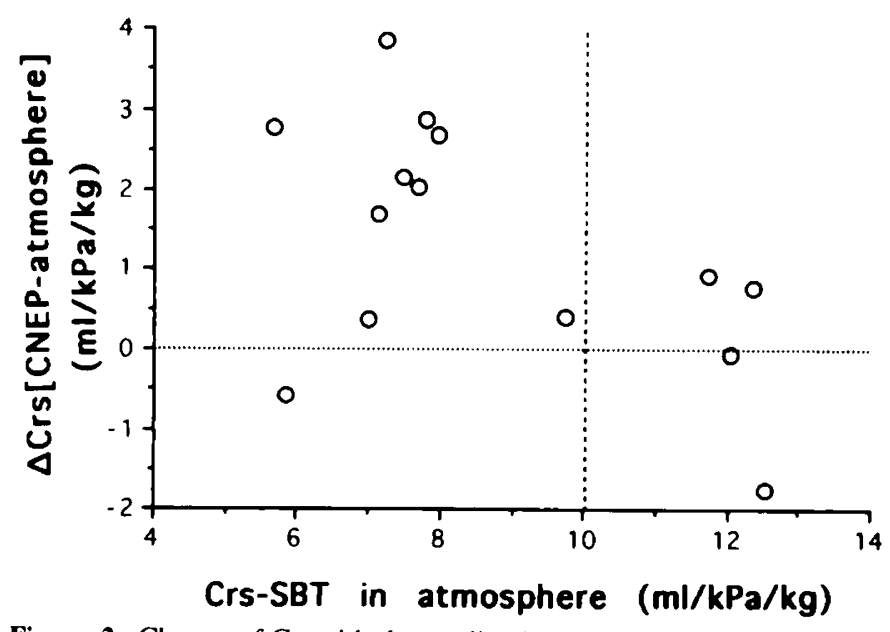

Figure 2. Change of $\mathrm{C}_{\mathrm{rs}}$ with the application of CNEP (using the SBT) corrected for body weight. Marked increase in infants with baseline $C_{r s}$ below $10 \mathrm{~mL} \cdot \mathrm{kPa}^{-1} \cdot \mathrm{kg}^{-1}$ (upper left quadrant). 
Table 4. Respiratory mechanics in three infants with and without neck seal

\begin{tabular}{|c|c|c|c|c|c|c|}
\hline & \multicolumn{2}{|c|}{ Infant 1} & \multicolumn{2}{|c|}{ Infant 2} & \multicolumn{2}{|c|}{ Infant 3} \\
\hline & Without & With & Without & With & Without & With \\
\hline PCA (wk) & 35 & & 35 & & 36 & \\
\hline Weight (kg) & 2.02 & & 2.30 & & 3.2 & \\
\hline$V_{T}(m L)$ & $19.1(2.6)$ & $17.3(2.5)$ & $11.6(0.8)$ & $11.7(0.8)$ & $17.7(2.8)$ & $17.2(4.8)$ \\
\hline$f_{\mathrm{R}}$ & $45.7(7.9)$ & $41.5(6.5)$ & $70.1(10.6)$ & $81.7(5.9)$ & $67.8(5.4)$ & $75.2(5.2)$ \\
\hline $\mathrm{C}_{\mathrm{rs}}\left(\mathrm{mL} \cdot \mathrm{kPa}^{-1}\right)$ & $37.8(3.7)$ & $33.2(4.5)$ & $10.2(0.7)$ & $9.1(1.2)$ & $20.9(1.1)$ & $23.1(5.3)$ \\
\hline$R_{r s}\left(\mathrm{kPa} \cdot \mathrm{L}^{-1} \cdot \mathrm{s}\right)$ & $6.7(0.9)$ & $6.8(0.9)$ & $7.3(0.5)$ & $8.2(0.7)$ & $6.1(1.3)$ & $4.8(1.4)$ \\
\hline
\end{tabular}

* PCA, postconceptional age; $f_{\mathrm{R}}$, respiratory rate per min. Results are expressed as mean (SD).

infants showed an increase in $\mathbf{R}_{\mathrm{rs}}(29$ to $33 \%$ ), and the remaining two demonstrated only minimal changes (Fig. 3). The group difference by paired $t$ test of $-2.0 \mathrm{kPa} \cdot \mathrm{L}^{-1} \cdot \mathrm{s}$ (95\% CI -2.87 to 0.96$)$ failed to reach statistical significance.

Four infants remained asleep long enough for us to repeat measurements in atmosphere after discontinuation of CNEP. Measurements were commenced 10 to $15 \mathrm{~min}$ after return to atmospheric pressure. In all four infants, values of respiratory timing and mechanics (SBT successful in three of four infants, MOT in one of four) returned to within $12 \%$ ( 1 to $12 \%$, median $9 \%$ ) of the initial measurement at atmospheric pressure.

As summarized in Table 4, the neck seal did not have any adverse effect on respiratory mechanics as assessed using the SBT at atmospheric pressure.

Lung volume. Continuous recording of $\mathrm{V}_{\mathrm{T}}$ on discontinuation of CNEP to assess the change in the EEL was feasible in eight of 18 infants who remained settled after return to atmospheric pressure. In these eight infants, the median decrease of the EEL immediately after the discontinuation of CNEP was $3.7 \mathrm{~mL}$ (range 0.0 to $9.4 \mathrm{~mL}$ ) (Fig. $4 A$ ). In two infants, a short apneic pause (3 $\mathrm{s}$ in one infant, $3.5 \mathrm{~s}$ in the other) on return to atmospheric pressure caused a transient decrease in lung volume that was immediately followed by a rise in EEL similar to that observed during CNEP (Fig. $4 B$ ). In the remaining 10 infants, arousal or transition to a very irregular breathing pattern on discontinuation of CNEP made meaningful interpretation of the time-based $V_{T}$ trace impossible.

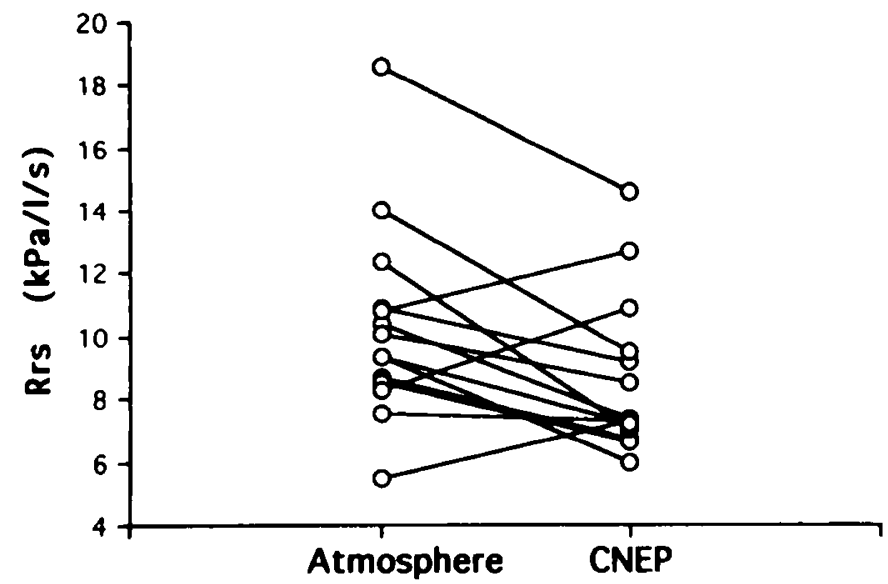

Figure 3. Change of $R_{r s}$ with the application of CNEP.

\section{DISCUSSION}

Although most clinical studies have shown a beneficial effect of continuous negative pressure ventilatory support for neonates and infants with respiratory failure, there are still controversies regarding the underlying physiologic effects.

Timing. The consistent fall in respiratory rate during CNEP that was noted in this study resulted predominantly from a marked increase in $t_{E}$ and probably reflects increased tonic vagal activity arising from stretch receptor stimulation (increased transpulmonary pressure) during the application of CNEP. These results are consistent with previously published data from healthy term babies $(15,23)$, although results from healthy preterm infants included in the same study were more variable.

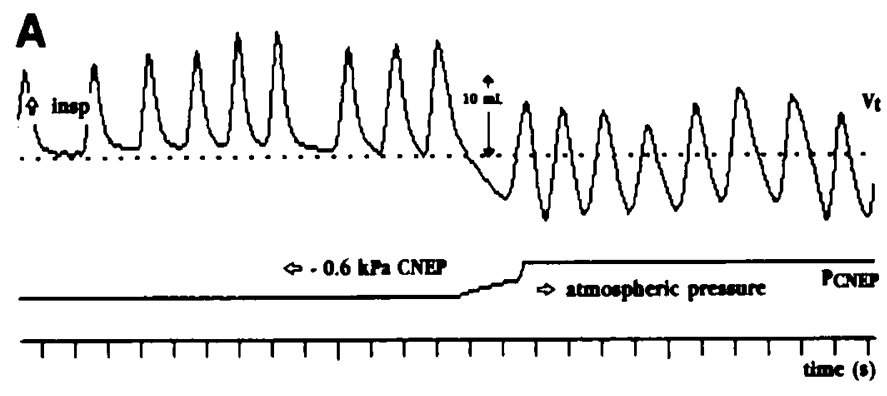

B

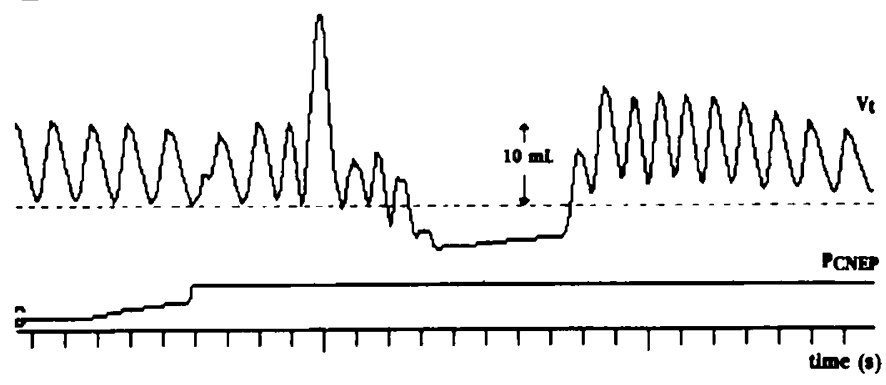

Figure 4. $A$, Continuous recording of $\mathrm{V}_{\mathrm{T}}$ and tank pressure $\left(P_{\mathrm{CNEP}}\right)$ during discontinuation of CNEP: initial change of the EEL ( $8.5 \mathrm{~mL}) . B$, Brief apnea with initial decrease in lung volume counterbalanced by increase in dynamic elevation of resting lung volume; note increased respiratory rate with short $t_{E}$ after discontinuation of CNEP. 
In the present study, end-inspiratory airway occlusions resulted in the prolongation of $t_{E}$ as previously demonstrated among healthy newborns (18). However, as previously noted by Stark and Frantz (15), who used endexpiratory occlusions to investigate phasic vagal activity, this effect was not influenced by the application of CNEP. To interpret these findings, it is necessary to consider the effects of CNEP on lung and $V_{T}$.

In their group of eight healthy preterm infants, Stark and Frantz (15) found a mean increase of 7.7 (SD 2.1) mL in EEL on application of approximately $0.6 \mathrm{kPa}$ CNEP. The smaller increase found in the present study can be partially explained by the relatively low values of $C_{r s}$ in many of our infants. Nevertheless, the mean observed change of $3.7 \mathrm{~mL}$ was slightly lower than predicted, inasmuch as with an applied pressure of $-0.6 \mathrm{kPa}$ (approximately $50 \%$ of which is probably transmitted to the mediastinal structures) and a mean compliance of 24 $\mathrm{mL} \cdot \mathrm{kPa}^{-1}$ one would predict a lung volume change of about $7 \mathrm{~mL}$. However, there was evidence from both the time-based $V_{T}$ trace (Fig. 4) and the reduced volume intercept from the MOT and SBT data (Table 3) $\lambda$ that the prolongation of $t_{E}$ resulted in less dynamic elevation of lung volume during CNEP than while the infants were breathing at atmospheric pressure, thereby partially compensating for any changes induced by CNEP. The flaccid rib cage in neonates presents a considerable threat for undue lung collapse during expiration, a tendency that is counterbalanced by a variety of breathing strategies including postinspiratory diaphragmatic braking, laryngeal adduction, and a rapid respiratory rate (short $t_{E}$ ) (24). The potent vagally mediated reflex control exerted by the pulmonary stretch receptors was reflected by marked prolongation of $t_{E}$ in response to presumably relatively small increases in transpulmonary pressure during this study. This supports the concept that expiratory control (and hence alterations in the rate at which afferent input to these stretch receptors decreases) plays an important role in the central regulation of breathing pattern in the young infant.

Because the relative prolongation of $t_{E}$ after occlusion was very similar before and after application of CNEP, whereas even small changes in FRC induced marked prolongation of $t_{E}$, our results support the hypothesis previously proposed by Stark and Frantz (15) that application of CNEP resets tonic vagal activity and shifts the $V_{T^{-}} t_{1}$ relationship upward. Furthermore, because $t_{E}$ was prolonged on CNEP whereas $t_{1}$ was relatively unchanged, it is apparent that, as previously suggested by Martin et al. (25) but in contrast to Clark and von Euler's concept of respiratory control (26), tonic stretch receptor stimulation must act to prolong $t_{E}$ independently of effects on $t_{1}$.

The variable effects of continuous distending pressure on respiratory timing reported by other authors is difficult to interpret without independent details of $t_{E}$ and $t_{1}(12$, 13). However, it appears that prolongation of $t_{E}$ and reduction in respiratory rate reflect a beneficial effect of
CNEP or continuous positive airway pressure with respect to optimizing lung volume $(15,27)$. In contrast, an increase in respiratory rate may reflect adverse effects such as may occur if the lungs are unevenly or overinflated.

Mechanics. In the present study, attempts were made to assess respiratory mechanics using both the MOT and the SBT to increase confidence in the reported results $(20,28)$. In contrast to most previously published data, we found that CNEP had no adverse effects on compliance and that highly significant increases occurred among those infants with low baseline levels. Application of continuous distending pressure has been reported to increase abdominal expiratory activity in animals (29), which might have resulted in a reduction in $\mathrm{C}_{\mathrm{rs}}$ during CNEP. However, there was no evidence of increased abdominal activity in this study, and we took care to accept data only when a clearly defined pressure plateau occurred during occlusion (17). Alternatively, it is possible that the increased $C_{\mathrm{rs}}$ could have resulted from increased relaxation of chest wall musculature (i.e. an increase in chest wall compliance) during CNEP. However, because the chest wall is highly compliant in preterm infants (30) and contributes a relatively small proportion to total $C_{r s}$, especially in the presence of lung disease, the observed changes are more likely to reflect changes in lung compliance.

Because the influence of CNEP on absolute lung volume appeared to be minimal, other mechanisms to explain the observed increase in $\mathrm{C}_{\mathrm{rs}}$ have to be considered. In those infants with persistent lung disease, the application of negative extrathoracic pressure may result in ventilation of previously collapsed areas of the lungs with redistribution of volume from overdistended to reopened units, resulting in an increase of compliance without any significant change in overall lung volume. The observed fall in respiratory rate and the increase in compliance with only minimal changes in $V_{\mathrm{T}}$ results in a decrease of the work of breathing, which may account for some of the beneficial effects reported with the clinical application of CNEP.

Using esophageal manometry to assess $\mathrm{C}_{\mathrm{L}, \mathrm{dyn}}$, both and Milner et al. (12) and Bancalari et al. (13) found a significant decrease in $C_{L, d y n}$ in their groups of normal term neonates and infants with RDS. The fact that neither of these groups reported a significant fall in respiratory rate during application of CNEP may indicate that FRC had not been optimized during these studies. It has been hypothesized that CNEP may result in overexpansion of ventilated areas of the lung while failing to reexpand collapsed alveoli, thus bringing the ventilated units to the flattened portion of the pressure-volume curve and resulting in the significant reductions in compliance that have sometimes been observed. Although this explanation may be reasonable for infants with lung disease, it is unlikely to explain the decrease in compliance previously reported in the group of healthy neonates (13). A far greater change in lung volume is necessary to affect the 
compliance of healthy lungs adversely (31). The effect of continuous positive airway pressure is subject to similar controversies: although some studies have shown adverse effects on compliance $(12,32)$ with the application of continuous positive airway pressure, which have been explained by inhomogeneous distribution of pressure with overdistension of ventilated units, others have found an improvement with different levels of positive endexpiratory pressure until a normal FRC was achieved (33). Recent studies investigating the effect of CNEP in normal newborn piglets by using a negative-pressure system identical with that in the present study found that $\mathrm{C}_{\mathrm{L}, \mathrm{dyn}}$ remained unchanged initially, with a subsequent increase reaching significance after $2 \mathrm{~h}$ in CNEP (14). It remains unclear how long the effect of CNEP will last. The same studies in piglets suggest that there might be a prolonged effect on compliance after discontinuation of CNEP despite lung volume returning to baseline values. However, in four infants who remained asleep long enough for us to repeat the measurements of respiratory mechanics, values within $10 \mathrm{~min}$ after return to atmospheric pressure were similar to those obtained before application of CNEP. We did not randomize the order in which measurements were performed in this study, because pilot work demonstrated that infants were more likely to arouse on discontinuation of CNEP than on its application, and the total duration of time available for study was limited in these unsedated infants.

As might be expected from a group of infants recovering from RDS, mean respiratory resistance in atmospheric pressure was slightly greater than commonly observed among healthy preterm infants $(20,22)$. The SBT measures total resistance of the respiratory system during expiration and hence gives higher values than when mechanics are assessed using esophageal manometry. $R_{r s}$ from 24 healthy preterm infants $(1.4-2.6 \mathrm{~kg})$ recently studied in our laboratory ranged from 3.2 to 10.9 $\mathrm{kPa} \cdot \mathrm{L}^{-1} \cdot \mathrm{s}^{-1}$ (mean $7.00 \pm 1.7 \mathrm{kPa} \cdot \mathrm{L}^{-1} \cdot \mathrm{s}^{-1}$; unpublished data), a range that was exceeded by four infants in the present study. Although $R_{r s}$ tended to decrease most in those infants with the highest baseline values, there was no statistically significant effect of CNEP on this parameter. The effect of low levels of CNEP on $R_{r s}$ may be minimal in infants with low compliance but relatively normal airways. The greatest difference is likely to be observed in those with relatively normal compliance but obstructed airways, i.e. those with bronchiolitis or severe CLD, in whom the application of increased transpulmonary pressure should improve airway patency. Hence, some physiologic effects of CNEP may be disease specific.

Ideally, respiratory mechanics would have been performed in atmospheric pressure before application of the neck seal and repeated once the infant was in CNEP. However, the disturbance caused by applying the neck seal and positioning the baby within the tank precluded this approach due to the limited time available to study these unsedated infants. Nevertheless, measurements at atmospheric pressure obtained in three infants with and without the neck seal in situ suggest that this did not influence the measurements in any adverse way (Table 4). Clinically, the neck seal was well tolerated by all infants, with no apparent airway obstruction and no obvious change in respiratory rate or pattern of breathing.

In summary, we assessed the effect of the application of $-0.6 \mathrm{kPa} \mathrm{CNEP}$ on passive respiratory mechanics and respiratory timing in 18 infants recovering from neonatal RDS. During CNEP, most infants showed a significant decrease in respiratory rate, which was predominantly due to an increase of the $t_{E}$. $C_{r s}$ improved only in those infants with low compliance values in atmosphere. There was no significant change in $R_{r s}$.

This study was performed in infants recovering from RDS rather than in infants during the acute phase of the disease because infants requiring ventilation are not routinely managed on CNEP in our unit. Nevertheless, because many of the infants still demonstrated residual abnormalities of respiratory mechanics at the time of the study, our results suggest that the clinical effects of negative extrathoracic pressure support may be partially attributable to its beneficial effects on respiratory mechanics in infants with respiratory disease.

\section{REFERENCES}

1. Woollam CHM 1976 The development of apparatus for intermittent pressure respiration (1) 1832-1918. Anaesthesia 31:537-547

2. Silverman WA, Sinclair JC, Gandy GM, Finster M, Bauman WA, Agate FJ 1967 A controlled clinical trial of management of respiratory distress syndrome in a body-enclosing respirator 1. Evaluation of safety. Pediatrics 39:740-748

3. Stahlmann MT, Malan AF, Shepard FM, Blankenship WJ, Young WC, Gray J 1970 Negative pressure assisted ventilation in infants with hyaline membrane disease. J Pediatr 76:174-182

4. Fanaroff AA, Cha CC, Sosa R, Crumrine RS, Klaus MH 1973 Controlled clinical trial of continuous negative external pressure in the treatment of severe respiratory distress syndrome. J Pediatr 82:921-928

5. Outerbridge EW, Roloff DW, Stern L 1972 Continuous negative pressure in the management of severe respiratory distress syndrome. J Pediatr 81:384 391

6. Chernick V, Vidyasagar D 1972 Continuous negative chest wall pressure in hyaline membrane disease: one year experience. Pediatrics 49:753-760

7. Stocks J, Godfrey S 1976 The role of artificial ventilation, oxygen and CPAP in the pathogenesis of lung damage in neonates: assessment by serial measurements of lung function. Pediatrics $57: 352-362$

8. Samuels MP, Southall DP 1989 Negative extrathoracic pressure in treatment of respiratory failure in infants and young children. BMJ 299:1253-1257

9. Cvetnic WG, Cunningham MD, Sills JH, Gluck L 1990 Reintroduction of negative pressure ventilation in neonates: two-year experience. Pediatr Pulmonol 8:245-253

10. Raine J, Wright TAM, Samuels MP. Southall DP, Modi N, Harvey D, Spencer A, Brookfield DSK 1991 The use of continuous negative extrathoracic pressure in neonatal respiratory failure. In: Lafeber $H N$ (ed) Fetal and Neonatal Physiological Measurements. Excerpta Medica, London, pp $265-$ 270

11. Sills JH, Cvetnic WG, Pietz J 1989 Continuous negative pressure in the treatment of infants with pulmonary hypertension and respiratory failure. J Perinatol 9:43-48

12. Milner AD, Saunders RA, Hopkin JE 1977 Effects of continuous distending pressure on lung volumes and lung mechanics in the immediate neonatal period. Biol Neonate 31:111-115

13. Bancalari E, Garcia OL, Jesse MJ 1973 Effects of continuous negative pressure on lung mechanics in idiopathic respiratory distress syndrome. Pediatrics 51:485-493

14. Mundie TG, Easa D, Finn L, Stevens EL, Hashiro GM, Uyehara CFT 1992 Effects of two hours of continuous negative extrathoracic pressure (CNEP) on pulmonary function and hemodynamics in ventilated piglets. Clin Res 40:84(abstr)

15. Stark AR, Frantz ID 1979 Prolonged expiratory duration with elevated lung volume in newborn infants. Pediatr Res 13:261-274 
16. American Thoracic Society/European Respiratory Society 1993 Respiratory mechanics in infants: physiological evaluation in health and disease. Am Rey Respir Dis 147:474-496

17. Dezateux CA, Fletcher ME, Rabbette PS, Stanger LJ, Stocks J 1991 A manual of infant lung function testing. Portex Anaesthesia, Intensive Therapy and Respiratory Medicine Unit, Institute of Child Health, London, ISBN 0 951895605

18. Rabbette PS, Costeloe KL, Stocks J 1991 Persistence of the Hering-Breuer reflex beyond the neonatal period. J Appl Physiol 71:474-480

19. Prechtl HFR 1974 The behavioural states of the newborn infant (a review). Brain Res 76:185-212

20. Gappa M, Rabbette PS, Costeloe KL, Stocks J 1993 Assessment of passive respiratory compliance in healthy preterm infants: a critical evaluation. $\mathrm{Pe}$ diatr Pulmonol 15:304-311

21. Migdal M, Dreizzen E, Praud JP, Vial M, Dehan M, Chambille B, Gaultier C 1987 Compliance of the total respiratory system in healthy preterm and fullterm newborns. Pediatr Pulmonol 3:214-218

22. Haouzi P, Marchal JP, Monin P, Vert P 1992 Respiratory mechanics in spontaneously breathing term and preterm neonates. Biol Neonate $60: 350-360$

23. Stark AR, Frantz ID 1979 Lung volume changes, occlusion pressure and chest wall configuration in human infants. Pediatr Res 13:250-256

24. Kosch P, Davenport P, Wozniak J, Stark A 1985 Reflex control of expiratory duration in newborn infants. J Appl Physiol 58:575-581
25. Martin RJ, Orken A, Katona PG, Klaus MH 1978 Effect of lung volume on expiratory time in the newborn infant. J Appl Physiol 45:18-23

26. Clark FJ, von Euler C 1972 On the regulation of the depth and rate of breathing. J Physiol 222:267-295

27. Schulze A, Mädler HJ, Gehrhardt B, Schaller P, Gmyrek D 1990 Titration of continuous positive airway pressure by the pattern of breathing: analysis of How-volume-time relationships by a non-invasive computerized system. $\mathrm{Pe}$ diatr Pulmonol 8:96-103

28. England SJ 1988 Current techniques for assessing pulmonary function in the newborn and infant: advantages and limitations. Pediatr Pulmonol 4 $48-53$

29. Bishop B, Bachofen $H 1972$ Vagal control of ventilation and respiratory muscle during elevated pressures in the cat. J Appl Physiol 32:103-112

30. Gerhard T, Bancalari $\mathrm{E}$ 1980 Chestwall compliance in full-term and premature infants. Acta Paediatr Scand 69:359-364

31. Nightingale DA, Richards CC 1965 Volume-pressure relations of the respiratory system of curarized infants. Anesthesiology 26:710-714

32. Saunders RA, Milner AD, Hopkin IE 1976 The effects of continuous positive airway pressure on lung mechanics and lung volumes in the neonate. Biol Neonate 29:178-186

33. Sivan Y, Deakers TW, Newth CJL 1991 Effect of positive end-expiratory pressure on respiratory compliance in children with acute respiratory failure. Pediatr Pulmonol 11:103-107 